\title{
Understanding the Impact of Flow Rate and Recycle on the Conversion of a Complex Biorefinery Stream Using a Flow-Through Microbial Electrolysis Cell
}

\author{
Alex J. Lewis ${ }^{\mathrm{a}, \mathrm{d}}$, Abhijeet P. Borole ${ }^{\mathrm{a}, \mathrm{b}, \mathrm{c}^{*}}$ \\ ${ }^{a}$ The University of Tennessee, Knoxville TN 37996. \\ ${ }^{\mathrm{b}}$ Biosciences Division, Oak Ridge National Laboratory, Oak Ridge, TN 37831-6226 d \\ ${ }^{c}$ Bredesen Center for Interdisciplinary Research and Education, The University of Tennessee, \\ Knoxville 37996 \\ *Corresponding author: borolea@ ornl.gov, Fax: (865) 5746442 \\ A manuscript submitted to Biochemical Engineering Journal
}

Notice of Copyright:

This manuscript has been co-authored by UT-Battelle, LLC under Contract No. DE-AC05-000R22725 with the U.S. Department of Energy. The United States Government retains and the publisher, by accepting the article for publication, acknowledges that the United States Government retains a non-exclusive, paid-up, irrevocable, world-wide license to publish or reproduce the published form of this manuscript, or allow others to do so, for United States Government purposes. The Department of Energy will provide public access to these results of federally sponsored research in accordance with the DOE Public Access Plan (http://energy.gov/downloads/doe-public-access-plan)

\begin{abstract}
The effect of flow rate and recycle on the conversion of a biomass-derived pyrolysis aqueous phase in a microbial electrolysis cell (MEC) were investigated to demonstrate production of renewable hydrogen in biorefinery. A continuous MEC operation was investigated under onepass and recycle conditions using the complex, biomass-derived, fermentable, mixed substrate feed at a constant concentration of $0.026 \mathrm{~g} / \mathrm{L}$, while testing flow rates ranging from 0.19 to 3.6 $\mathrm{mL} / \mathrm{min}$. This corresponds to an organic loading rate (OLR) of 0.54 to $10 \mathrm{~g} / \mathrm{L}-$ day. Mass transfer issues observed at low flow rates were alleviated using high flow rates. Increasing the flow rate
\end{abstract}


to $3.6 \mathrm{~mL} / \mathrm{min}$ (3.7 $\mathrm{min} \mathrm{HRT}$ ) during one-pass operation increased the hydrogen productivity 3 fold, but anode conversion efficiency (ACE) decreased from 57.9\% to 9.9\%. Recycle of the anode liquid helped to alleviate kinetic limitations and the ACE increased by 1.8 -fold and the hydrogen productivity by 1.2-fold compared to the one-pass condition at the flow rate of 3.6 $\mathrm{mL} / \mathrm{min}(10 \mathrm{~g} / \mathrm{L}-\mathrm{d}$ OLR). High COD removal was also achieved under recycle conditions, reaching $74.2 \pm 1.1 \%$, with hydrogen production rate of $2.92 \pm 0.51 \mathrm{~L} / \mathrm{L}$-day. This study demonstrates the advantages of combining faster flow rates with a recycle process to improve rate of hydrogen production from a switchgrass-derived stream in the biorefinery.

\section{Keywords}

Switchgrass, Bio-oil aqueous phase; Pyrolysis, Integrated hydrogen production, Organic loading rate, Hydraulic retention time.

\subsection{Introduction}

Production of drop-in fuels from biomass requires deoxygenation of the biomass, since it contains over 35\% oxygen by weight [1]. Hydrogen generated via steam reforming of natural gas is a typical reductant for this process. Renewable hydrogen generated from biomass has potential to reduce greenhouse gas emissions to mitigate climate change. Microbial electrolysis is one such method to generate hydrogen for biorefinery application [2, 3]. Conversion of switchgrass to hydrogen was recently demonstrated using microbial electrolysis cells (MECs) [4]. The process involved pyrolysis of switchgrass to generate bio-oil and an associated aqueous stream rich in carbon, which was used as a feed for microbial electrolysis. The process generates an organic phase which serves as a feedstock for biofuel production using hydrogen generated via 
microbial electrolysis. Application of the combined pyrolysis-microbial electrolysis process in biorefineries requires further understanding of the influence of process and operating conditions on hydrogen production.

Several MEC configurations and process conditions have been studied for improving performance and conversion of waste streams into hydrogen. Integration of MECs into biorefineries may require development of continuous systems rather than batch systems to supply a steady stream of hydrogen for the hydrodeoxygenation reaction. Continuous MEC operation has been investigated previously for municipal wastewater treatment [5-7], winery wastewater [8], as well as MECs using model substrates [9-11]. Typical parameters studied for quantifying and understanding performance of continuous MECs include hydraulic retention time (HRT) and organic loading rate (OLR), which depend on flow rate and substrate concentration. However, the number of reports investigating these effects for complex substrates in continuous systems are limited. Typical HRTs for MEC range from a few hours to a day or more. Increasing the HRT has been reported to affect the hydrogen production rate as well as the efficiency of hydrogen production with mixed results $[5,13]$. The effect of OLR on bioanode efficiency and productivity has also been studied [6, 14], but primarily in microbial fuel cells (MFCs) [15-18]. The current output usually increases with increasing OLR, however, the coulombic efficiency, hydrogen recovery, and cathode efficiency can vary depending on other operational parameters. The type of substrate also makes a significant difference in the performance of the MEC. Use of fermentable substrates vs those which can be used directly by exoelectrogens, such as acetate, can lead to variations in performance depending on MEC design and operating conditions [6]. The effect of OLR and HRT on MEC performance is not well understood. The HRT, OLR and 
substrate concentration are inter-related and cannot truly be studied independently, as is typically done. For example, to reach a desired OLR either the HRT/flow rate of the system or the concentration of the feed has to be altered. Thus, when studying the effect of different OLR's, one of the other two variables will also be changing, so, only two of the three variables can be studied independently, while the third remains a dependent variable. Furthermore, the use of complex substrates or wastewater containing fermentable substrates as feed can significantly complicate these effects $[5,6]$. Understanding the influence of these operational parameters in MECs treating complex substrates requires insights into the mechanistic details of the process. The contribution of exoelectrogenic vs. fermentative and other accompanying biochemical reactions occurring in the MEC, as well as the kinetics and mass transfer issues underlying the processes have to be evaluated to provide a better understanding of the effects on MEC performance.

In this study, we investigate the effect of flow rate, which defines HRT and OLR at a given substrate concentration. We examine the effect of these variables on MEC performance treating a complex, biomass-derived pyrolysis aqueous phase [4], but is applicable to any complex wastewater stream. This is important for generation of hydrogen in the biorefinery, since it can allow upgrading of bio-oil to biofuels without the need for external hydrogen. Identifying the operating conditions to maximize hydrogen production is critical, so we investigated the effect of anode fluid recycle on MEC performance operated under continuous flow conditions using two continuously-fed, replicate MECs.. Our goal was to understand the performance of MECs fed with complex substrates such as bio-oil aqueous phase (BOAP) and development of continuous systems for application in the biorefinery. 


\subsection{Methods.}

\subsection{MEC construction and experimental set up.}

Two microbial electrolysis cells were constructed using carbon felt as anode material and Ptdeposited carbon as the cathode material (Figure 1). A carbon rod and stainless steel wire were used as current collectors, respectively, along with Nafion 115 as the separating membrane between the two electrode chambers. The anode and cathode volume were $16 \mathrm{~mL}$ each, while the projected area was $12.56 \mathrm{~cm}^{2}$. The cathode buffer was $100 \mathrm{mM}$ potassium phosphate. Additional details of the MEC construction are given elsewhere [4]. The MECs were operated in a continuous flow mode to study the effect of flow rate and substrate concentration on hydrogen production. 


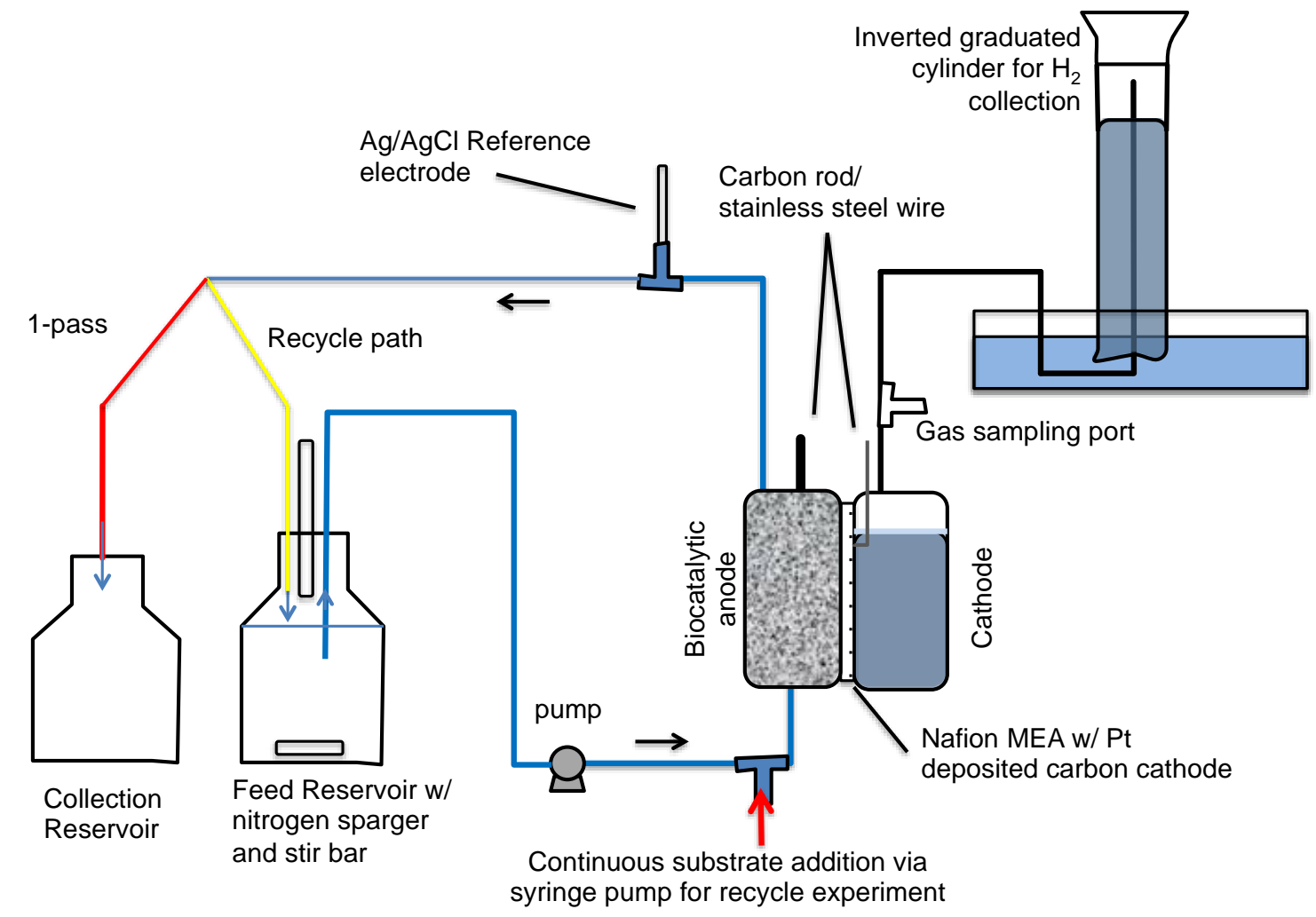

Figure 1. Schematic of MEC system investigating hydrogen production under one-pass and recycle conditions. Substrate was added directly into the feed reservoir for the one-pass condition, while it was added via the syringe pump into the flow line achieving the same OLR for the recycle conditions.

\subsection{Feedstock preparation for bioanode development.}

The substrate fed into the MEC anode was an aqueous portion of pyrolysate or bio-oil aqueous phase (BOAP) derived from switchgrass. The biomass was pyrolyzed in semi pilot augur reactor system, utilizing a residence time of 72 seconds at $500{ }^{\circ} \mathrm{C}$ to produce a bio-oil, which was then 
separated into an organic and aqueous phase by addition of deionized water (Oil:water ratio $=$ 1:4) $[4,19]$. The chemical oxygen demand of the BOAP generated through the process was 130 $\mathrm{g} / \mathrm{L}$. The main compounds within BOAP consist of organic acid, furans, and phenolic compounds, with more detail information provided in the Supplemental Information. The primary compounds include levoglucosan, acetic acid, hydroxymethylfurfural (HMF), 2-furfural, vanillic acid, 2-methoxyphenol, 3-ethylphenol, etc [4, 19]. The concentrated BOAP was diluted prior to use in order to minimize any additional effects of overloading and was fed into the MEC at different loading rates ranging from 0.54 to $10 \mathrm{~g} / \mathrm{L}$-day.

The MEC's used in this study were established and operated for $\sim$ one year prior to the experiments reported here. The anodes were inoculated from a set of reactors previously acclimated to BOAP to create a new set of duplicate reactors, MEC-A and MEC-B. Furthermore, replicate experiments were conducted in each reactor, producing 4 sets of data for each condition. Results are reported either as average of two replicates with data shown for each of the two MECs or as average of all 4 runs. The error bars describe the method of averaging. A minimal nutrient salt medium containing Wolf's mineral and vitamin solutions was used as reported previously [4]. Glucose was provided as a supplemental carbon source for growth of the biofilm in addition to BOAP during start-up. It was mixed with BOAP and fed continuously into the anode. The glucose concentration was gradually reduced from 50\% at the initial loading of 1 $\mathrm{g} / \mathrm{L}-\mathrm{d}$ to $0 \%$ (100\% BOAP) at the highest loading of $10 \mathrm{~g} / \mathrm{L}-\mathrm{d}$. Cyclic voltammetry was carried out every 1-2 weeks with a batch addition of $0.1 \mathrm{~g} / 1$ glucose and $0.1 \mathrm{~g} / \mathrm{l}$ BOAP separately to assess growth, current output, and BOAP utilization over the first two months of operation. During the period of 2-10 months post inoculation, the reactors were operated in both MFC and 
MEC modes. Prior to the beginning of this study, the reactors had been operated under only MEC conditions for the past 2 months using BOAP as the only substrate, with the anode poised at $-0.2 \mathrm{~V}$ vs $\mathrm{Ag} / \mathrm{AgCl}$ reference electrode. While additional experiments prior to this study did see the reactors reach loading of $10 \mathrm{~g} / \mathrm{L}$-d, long-term operation was limited to $2 \mathrm{~g} / \mathrm{L}$-d to avoid excess growth of non-exoelectrogens. However, the MECs were operated intermittently under

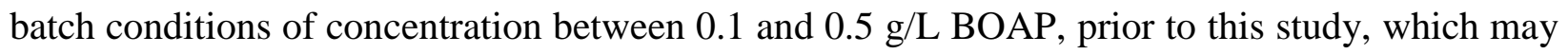
have resulted in growth of non-exoelectrogenic organisms and methanogens.

\subsection{One-pass and recycle operation}

The MECs were investigated via chronoamperometry by poising the anodes at $-0.2 \mathrm{~V}$ vs $\mathrm{Ag} / \mathrm{AgCl}$ reference electrode. Hydrogen production was studied under two process conditions with continuous substrate addition: a one-pass operation and a recycle operation. The one-pass operation consisted of continuous flow of anode fluid from a feed reservoir containing BOAP through the MEC, with the effluent collection in separate container. During the recycle operation, the anode liquid was continuously recycled to and from the feed reservoir and the BOAP substrate was added via a syringe using a concentrate into the flow line entering the anode as shown in Figure 1. A constant BOAP concentration of $0.026 \mathrm{~g} / \mathrm{L}$ was maintained in the flow line entering the anode for the majority of one-pass and recycle experiments to test the effect of flow rate on current and hydrogen production. For one-pass operation, the MEC's were operated at different flow rates ranging from $0.19 \mathrm{~mL} / \mathrm{min}$ to $3.6 \mathrm{~mL} / \mathrm{min}$, corresponding to an $\mathrm{HRT}$ of 70.6 to $3.7 \mathrm{~min}$. The corresponding OLR ranged from $0.54 \mathrm{~g} / \mathrm{L}-\mathrm{d}$ to $10 \mathrm{~g} / \mathrm{L}-\mathrm{d}$. For recycle operation, the range was slightly narrowed to $0.3 \mathrm{~mL} / \mathrm{min}$ to $3.6 \mathrm{~mL} / \mathrm{min}$. Figure $2 \mathrm{~A}$ shows the 
operating variables and the corresponding operational times for the various conditions. Figure 2B shows the resulting OLR and HRT corresponding to the operational conditions. The order of execution of the experiments was dictated by the time frame of the experiments, which were scheduled to maximize the number of experiments that could be run while facilitating sampling and operational changes. The conditions for the recycle experiments are shown in Figures $2 \mathrm{C}$ and 2D. An additional experiment was carried out at higher concentration of $0.3 \mathrm{~g} / \mathrm{L}$ at a flow rate of $0.3 \mathrm{~mL} / \mathrm{min}$, which served to compare high and low flow rates across the the same loading rate of $10 \mathrm{~g} / \mathrm{L}-\mathrm{d}$ with one-pass and recycle.

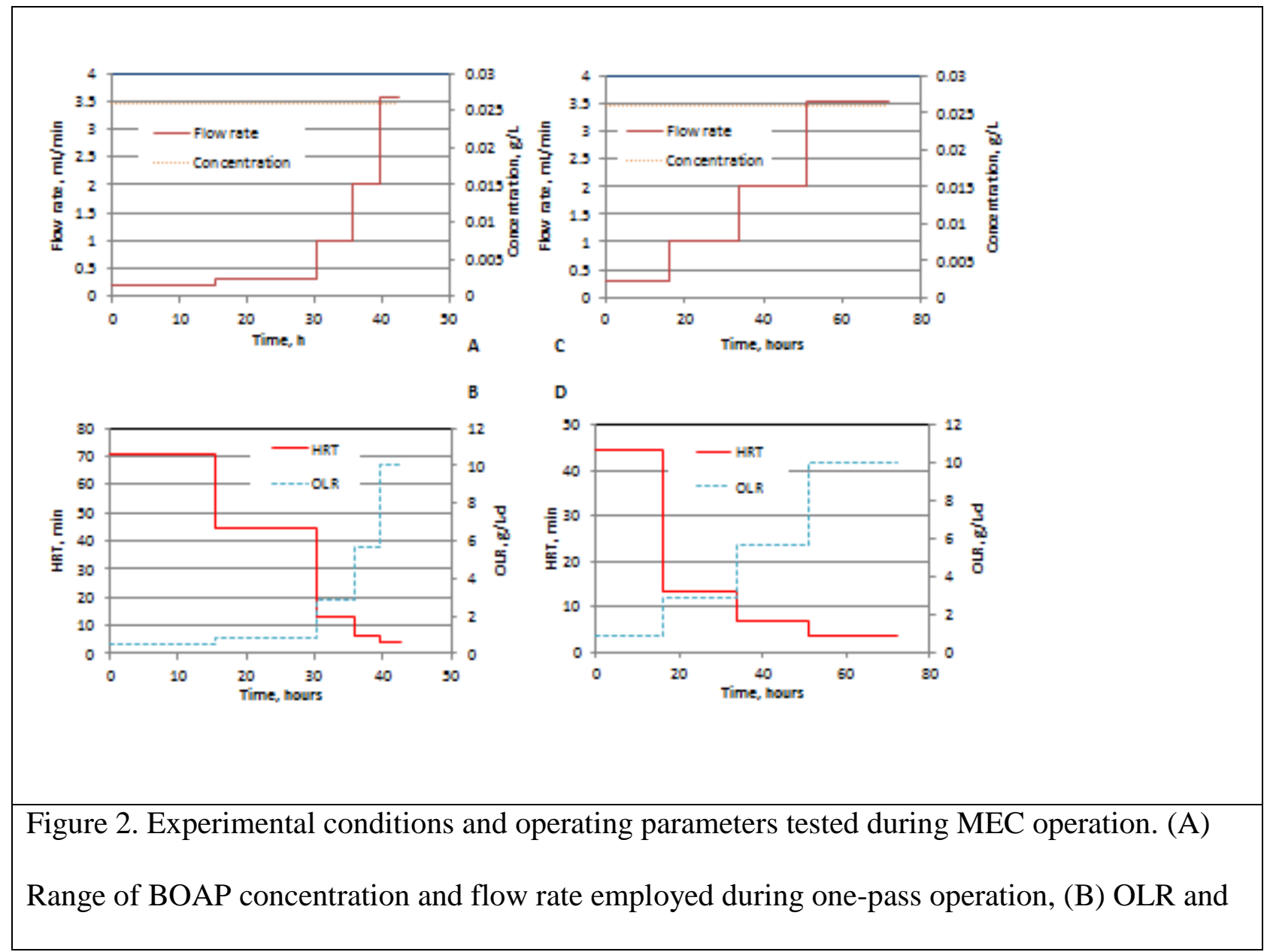


HRT corresponding to one-pass operation, (C) Range of BOAP concentration and flow rate employed during recycle operation, (D) OLR and HRT corresponding to recycle operation.

Prior to the start of each experiment, circulation of media and substrate were stopped to allow current output to decrease to the baseline level, while media was replaced and flushed from the lines, as well as through the anode. The cathode buffer was also replaced between experiments, except for those with short time frames where current output and hydrogen production would not likely result in $\mathrm{pH}$ changes (based on previous experimental observations). Anodes remained poised at $-0.2 \mathrm{~V}$ vs $\mathrm{Ag} / \mathrm{AgCl}$ at all times, even between experiments, so hydrogen measurements and current outputs were tracked upon re-starting flow of substrate for a specific condition. A Reference 3000 potentiostat/galvanostat/zero resistance ammeter (Gamry Instruments, Warminster PA) was used for all the experiments. Depending on the flow rate used for one-pass operation, most experiments were allowed to run between 4-24 h. A volume of $100 \mathrm{~mL}$ was used in the reservoir for recycle experiments.

\subsection{Analysis and calculations.}

At the end of each run, the volume displaced by hydrogen production was measured and gas samples for GC analysis were taken from the cathode outlet to confirm hydrogen production. Liquid samples were taken for high performance liquid chromatography (HPLC) analysis from the external anode reservoir for the recycle experiments and from the effluent collector for the one-pass experiments. A Jasco 2000Plus (Jasco analytical instruments) equipped with PU-2089S Plus pump, a MD-2018 Plus Photodiode Array detector (PDA), a RI-2031 Plus intelligent RI detector, and an AS-2055 Plus auto sampler was used to analyze HPLC samples for individual 
compound conversion. The liquid chromatography was conducted at $50.0^{\circ} \mathrm{C}$ using Bio-rad HPX$87 \mathrm{H}(300 \times 8 \mathrm{~mm})$ column with an injection volume of $20 \mu 1$. The mobile phase was $5 \mathrm{mM} \mathrm{H}_{2} \mathrm{SO}_{4}$ with a flow rate of $0.6 \mathrm{~mL} / \mathrm{min}$. COD analysis was also conducted to measure the extent of overall BOAP conversion. $2 \mathrm{~mL}$ samples were added to Hach HR COD (20-1500 mg/L COD) vials and digested in a Hach DRB 200 reactor at $150{ }^{\circ} \mathrm{C}$ for 2 hours. Digested samples were allowed to cool to room temperature and analyzed on Spectronic 20 Genesys with absorbance readings taken at $620 \mathrm{~nm}$..

Performance and conversion efficiency were characterized by anodic conversion efficiency (ACE), cathodic conversion efficiency (CCE), hydrogen efficiency (HE), hydrogen recovery (HRE), Coulombic efficiency (CE). ACE and HE are additional parameters based on the total substrate provided, and not on the COD that was removed. The formulas for ACE and CE are very similar, with CE using $\left(\mathrm{n}_{\mathrm{s}}\right)$ for moles of substrate removed and ACE uses the total COD added to the anode represented by $\left(\mathrm{n}_{\mathrm{T}}\right)$.

$$
C E / A C E=\frac{I_{o b s} t}{\left(n_{s} \text { or } n_{T}\right) n_{e} F}
$$

where $I_{o b s}$ is the current produced, $n_{e}$ is the number of electrons available per mol of substrate based on complete conversion to $\mathrm{CO}_{2}$, F: Faraday constant, and $\mathrm{t}$ is the duration of the experiment. HRE and HE equations are altered similarly, with HRE using ( $\triangle \mathrm{nCOD})$ for moles of COD removed and HEusing total COD added to the system (tCOD).

$$
H R E / H E=\frac{P V_{H 2} / R T}{2(\triangle n C O D \text { or } t C O D)}
$$

The other variables consist of $(\mathrm{P})$ for the atmospheric pressure, $\left(\mathrm{V}_{\mathrm{H} 2}\right)$ is the volume of hydrogen produced, $(\mathrm{R})$ is the gas constant, $(\mathrm{T})$ is the temperature in Kelvin. Cathode conversion was 
calculated as previously described, and is based on the ratio of hydrogen produced vs the theoretical amount that could be produced based on the average current generated over the length of the experiment $[4,10]$.

\section{Results and Discussion}

\subsection{Hydrogen production from switchgrass bio-oil aqueous phase.}

BOAP contains a wide spectrum of compounds such as phenolics, furans, and organic acids, resulting from the thermochemical pyrolytic conversion of lignocellulosic biomass . Our previous study demonstrated the ability to produce hydrogen from these compounds using switchgrass-derived BOAP via microbial electrolysis $[4,19]$. This current work set out to study a continuous MEC process and to identify the effect of flow rate on MEC performance. The results reported previously [4] only included operation under recycle conditions at a set flow rate of 3.6 $\mathrm{mL} / \mathrm{min}$, demonstrating an increase in current with increasing OLR up to the highest level tested

of $10 \mathrm{~g} / \mathrm{L}-\mathrm{d}$. This work expands the investigations to one-pass, continuous operation, at different flow rates, but at a constant feed concentration of $0.026 \mathrm{~g} / \mathrm{L}$. The hydrogen productivity for onepass operation increased with increasing flow rate, but plateaued at a flow rate of $2 \mathrm{~mL} / \mathrm{min}$ as shown in Figure 3, reaching 1.41 $\pm 0.14 \mathrm{~L}-\mathrm{H}_{2} / \mathrm{L}$-anode volume-day (referred to as L/L-day, henceforth). Hydrogen production under recycle conditions, also studied at different flow rates, resulted in a continued increase up to the highest flow rate studied, reaching a maximum of 2.92 $\pm 0.51 \mathrm{~L} / \mathrm{L}-\mathrm{d}$ at $3.6 \mathrm{~mL} / \mathrm{min}$. This is an improvement in the rate of hydrogen production by $107 \%$ compared to the one-pass condition. The effects of the operating conditions on anode and cathode processes leading to this improvement in hydrogen productivity are discussed below. The reproducibility of the MEC performance in the two replicate MECs (A and B) was 
remarkable with an average coefficient of variation of $6.57 \%$ for hydrogen productivity across the recycle experiments.

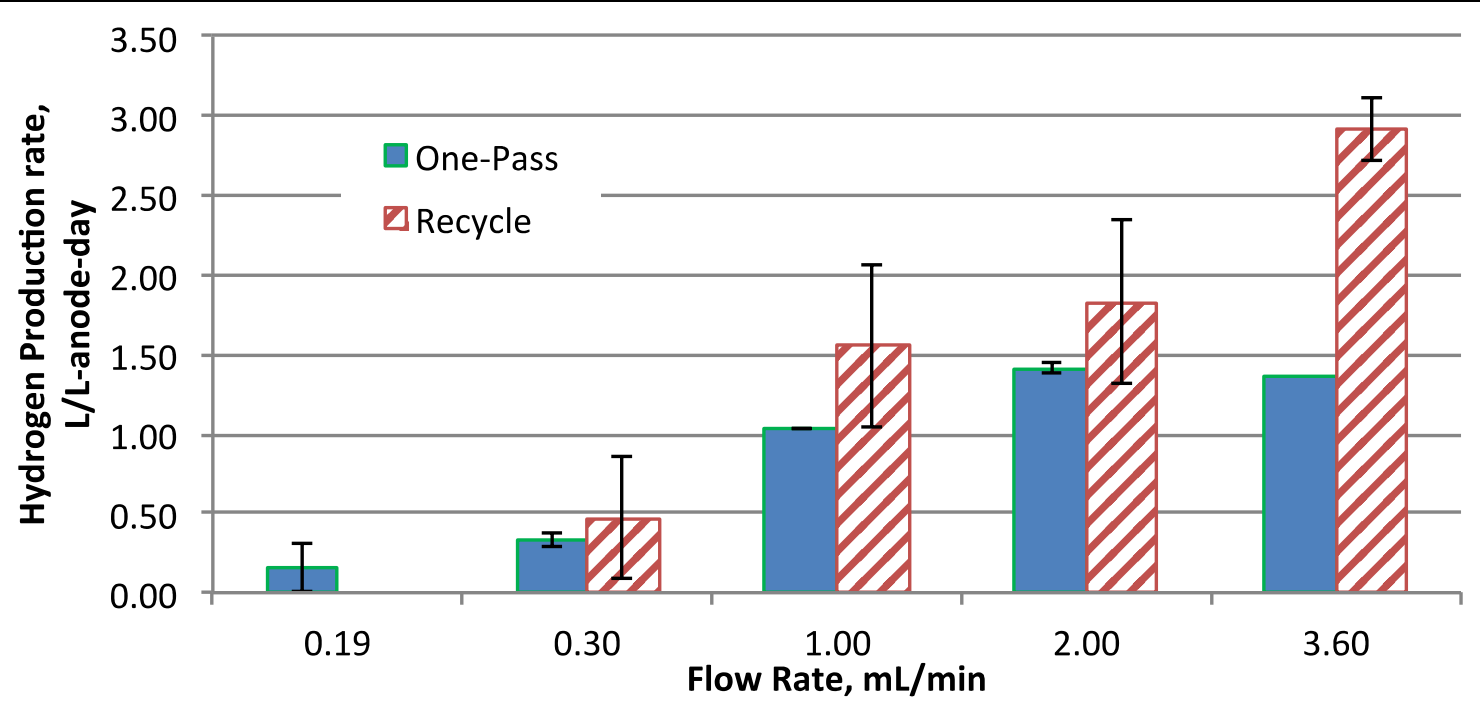

Figure 3. Rate of hydrogen production as a function of flow rate. The error bars represent standard deviation for two duplicate reactors.

\subsection{Effect of Flow rate on current density and efficiency during one-pass operation.}

The effect of flow rate on MEC performance was evaluated over 19-fold range. With BOAP concentration held constant at $0.026 \mathrm{~g} / \mathrm{L}$, this corresponds to an OLR range of 0.54 to $10 \mathrm{~g} / \mathrm{L}-\mathrm{d}$. Two replicate reactors were used, MEC-A and MEC-B, which performed with similar results. Referring to MEC-A, as the flow rate was increased from 0.19 to $3.6 \mathrm{~mL} / \mathrm{min}$, the average current density increased from $0.44 \mathrm{~A} / \mathrm{m}^{2} \pm 0.04$ to $1.46 \mathrm{~A} / \mathrm{m}^{2} \pm 0.11$. While the current density increased with flow rate, the anode conversion efficiency (ACE, current yield as a function of substrate provided) followed a reverse trend for the most part as shown in Figure 4. The average ACE was $55.6 \pm 4.6 \%$ at a flow rate of $0.19 \mathrm{~mL} / \mathrm{min}$, however, it decreased steadily to $9.9 \% \pm$ 
$0.7 \%$ as the flow rate was increased to $3.6 \mathrm{~mL} / \mathrm{min}$ as shown in Figure 4. Anode Coulombic efficiency (CE) was also determined based on COD analysis of the MEC influent and effluent as reported previously [4]. ACE and HE were used rather than CE and HRE because the change in COD for most one-pass experiments was below the error of analysis due to the low COD concentration used in these experiments. The results for ACE and HE were also reproducible in the two replicate reactors, MEC-A and B, which were operated under the same conditions. All the experiments conducted in this study used the same low BOAP concentration $(0.026$ $\mathrm{g} / \mathrm{L}$ ), which means that OLR and HRT both changed as function of the flow rate, simultaneously.

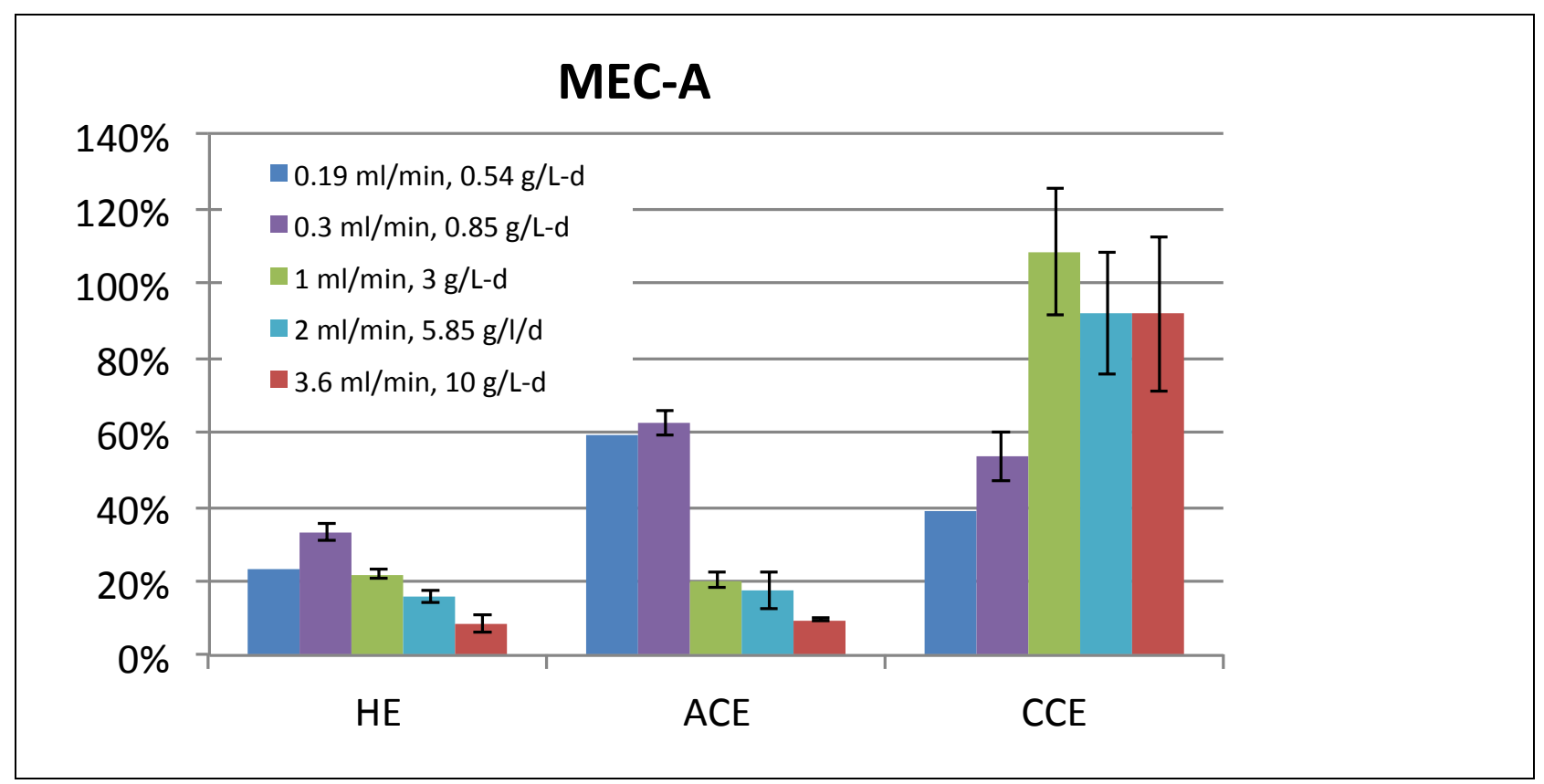




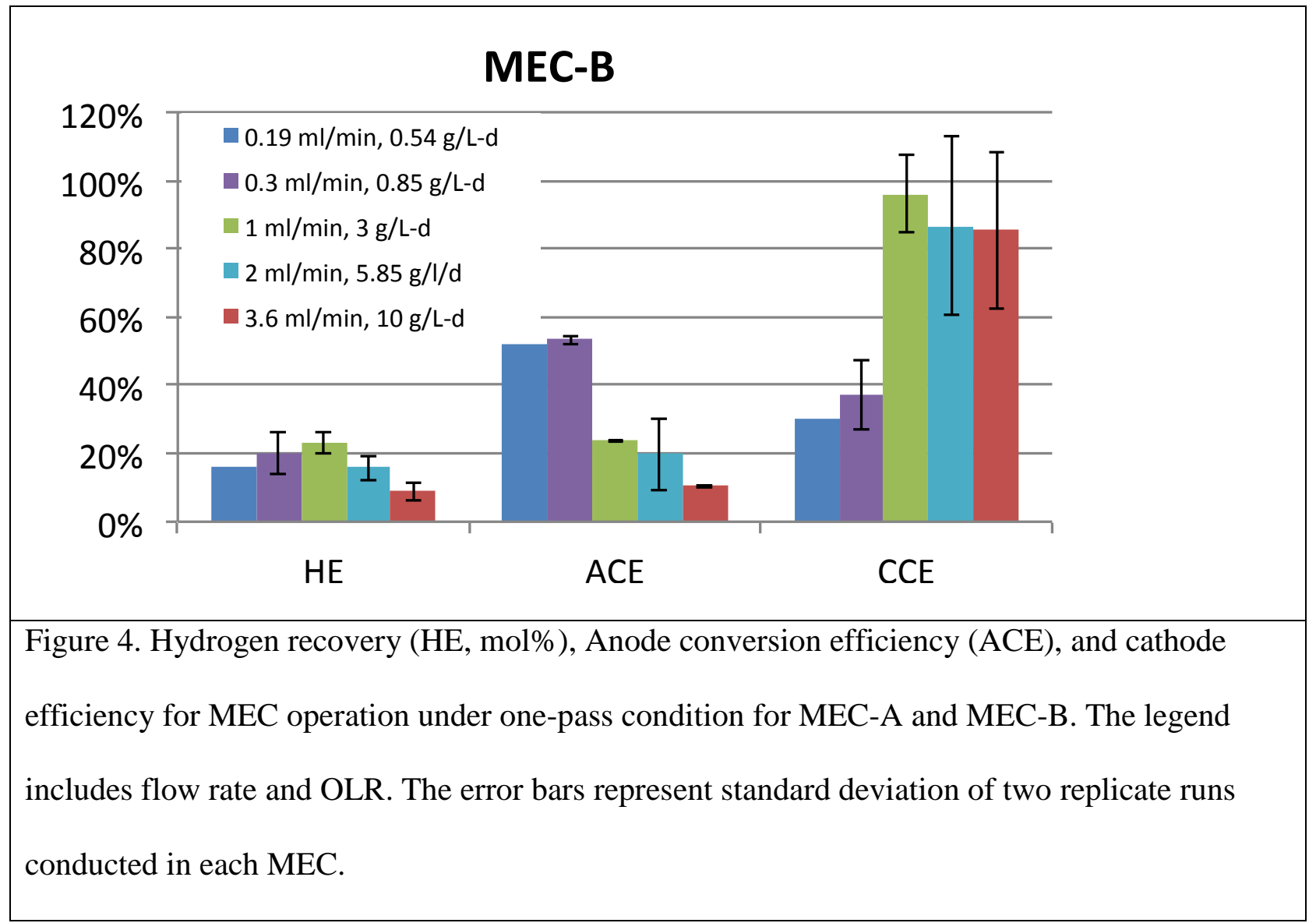

Compared to ACE, the cathode efficiency showed a reverse trend and increased from $34.55 \pm$ $6.29 \%$ to $88.6 \% \pm 4.5 \%$ as the flow rate was increased from 0.19 to $3.6 \mathrm{~mL} / \mathrm{min}$. There was greater variation in cathode efficiencies at the higher flow rates, which is likely due to the shorter run times, but the overall trend remains and shows a considerable drop off in CCE when flow is reduced below $1 \mathrm{~mL} / \mathrm{min}$. Since the anode potential was controlled in these experiments, the cathode potential varied as a function of the current produced. As the rate of substrate delivery to the anode (OLR) is increased, the number of electrons generated and transferred to the cathode increases, thus reducing the cathode potential to more negative values. At low flow rates, the potential difference $(\Delta \mathrm{V})$ between the anode and the cathode was smaller. At a flow rate of 0.19 $\mathrm{mL} / \mathrm{min}$, the $\Delta \mathrm{V}$ was only $0.66 \mathrm{~V}$. The low cathode efficiency observed at low flow rates was 
potentially due to the smaller potential difference between the two electrodes, and more positive value for the cathode. This hypothesis was tested by conducting an additional experiment by setting the $\Delta \mathrm{V}$ between the anode and cathode to $1.0 \mathrm{~V}$ (vs. $0.66 \mathrm{~V}$ which was reached when the anode was poised at $-0.2 \mathrm{~V}$ vs. $\mathrm{Ag} / \mathrm{AgCl}$ electrode). This was done at the flow rate of $0.3 \mathrm{~mL} / \mathrm{min}$ corresponding to an OLR of $0.85 \mathrm{~g} / \mathrm{L}-\mathrm{d}$, The higher $\Delta \mathrm{V}$ increased the CCE to $54.5 \%$, improving the cathode efficiency by $21 \%$. This indicates that the potential difference was at least partially responsible for the lower cathode efficiency. Studies carried out by Escapa et al. (2012) indicated that the benefits of increased voltage are not as pronounced at low OLR's, corroborating our modest increase [14]. The trend for HE is more complicated between the two reactors. On average, the HE increased initially from $19.4 \% \pm 5.4 \%$ at the lowest flow rate to $26.7 \pm 2.5 \%$ at $0.3 \mathrm{~mL} / \mathrm{min}$. From here, $\mathrm{HE}$ decreased with increasing flow rate to $8.8 \pm 0.2 \%$ at $3.6 \mathrm{~mL} / \mathrm{min}$. It is clear that HE decreases with increasing flow rate during one pass due to low ACE. However, when flow rate is reduced enough, HE begins to decrease due to the significant drop-off in CCE below $1 \mathrm{~mL} / \mathrm{min}$., Thus, a maximum HE would likely be obtained somewhere between a flow rate of 0.3 and $1 \mathrm{~mL} / \mathrm{min}$ when comparing the two replicate reactors. The drop in ACE and HE with increasing flow rate was suspected to be due to insufficient retention time for conversion during one-pass operation. This hypothesis was investigated further by recycling the anode effluent.

\subsection{Effect of anode recycle on MEC performance.}

Since the ACE decreased with increasing flow rate, the effect of recycle was examined as a potential way to boost conversion in the anode. The hypothesis is that when the anode fluid is recycled, the HRT would effectively increase to infinity, enabling higher conversion of the COD 
increasing current production and ACE. Figure 5 shows the current density as a function of time at a flow rate of 1 and $2 \mathrm{~mL} / \mathrm{min}$ under recycle conditions. The current production during the one-pass experiment is also shown for comparison. The results show that the current production increased significantly as a result of recycle at and beyond $1 \mathrm{~mL} / \mathrm{min}$.

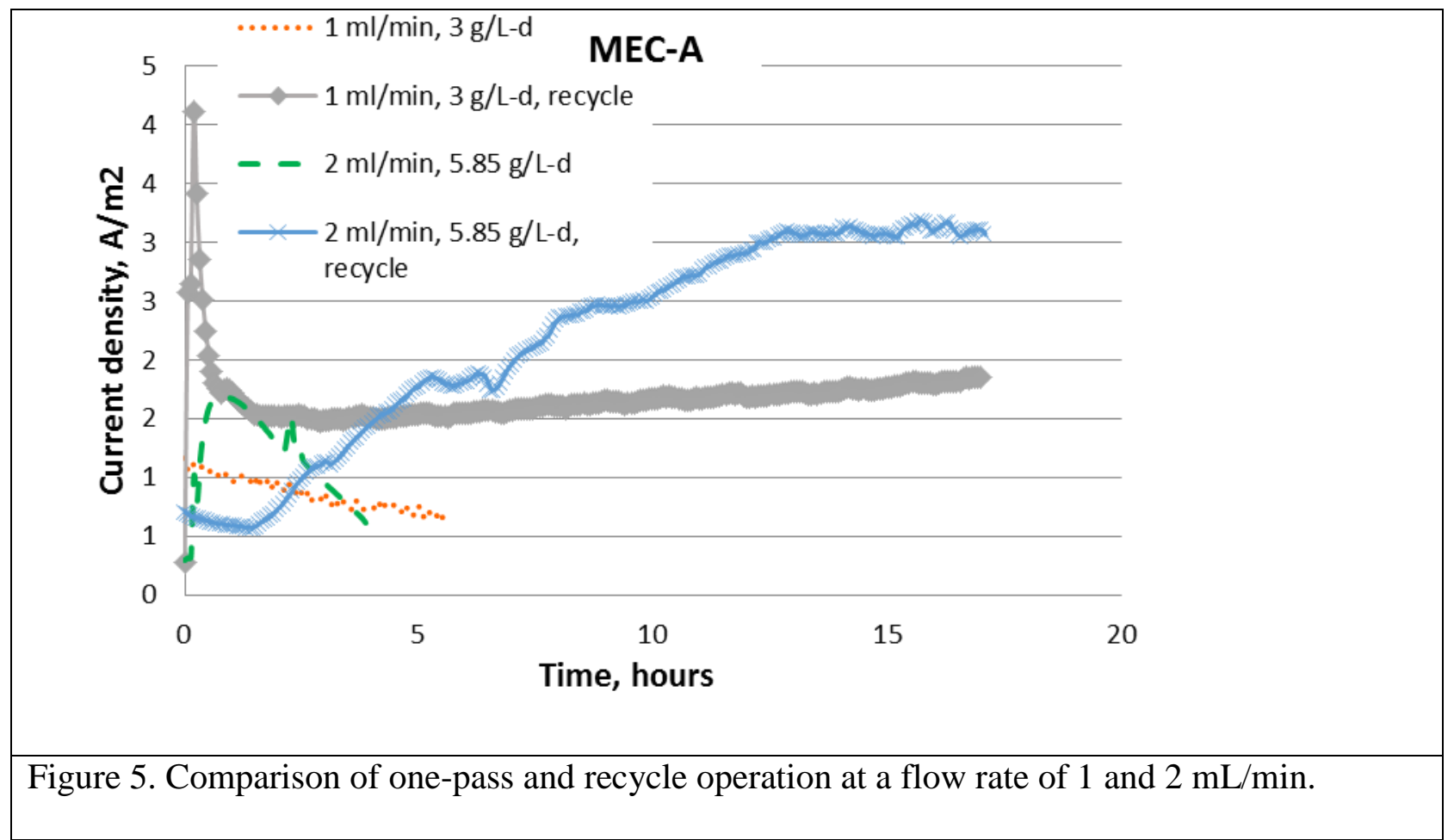

Figure 6 shows the comparison of the average current density achieved at different flow rates for the recycle and one-pass conditions. The current density increased by more than $120 \%$ at 3.6 $\mathrm{mL} / \mathrm{min}$ when the anode fluid was recycled. As shown in Figure 5, the current increased during the course of the run under recycle conditions, while it decreased under one-pass conditions. The trends were similar for all experiments at and above the flow rate of $1 \mathrm{~mL} / \mathrm{min}$, although the difference was more pronounced at the higher flow rates. To illustrate this effect graphically, the end-point current densities based on the final current obtained during each run were compared with the average current densities (Figure 6). For recycle, the average current densities were less 
than the end-point current densities, and the opposite was true for one-pass under most conditions as shown in Figure 6. The current produced during the start of the run was typically low and increased gradually with time as substrates and intermediates accumulated during recycle, resulting in higher endpoint currents. In the one-pass condition, faster flow rates alleviated mass transfer issues only up to a certain point due to the complex nature of the substrate, resulting in a reduction in current output at the highest flow rate due to the limited time the substrate spends in the anode. When the anode fluid is recycled, the effective retention time increases, allowing for enhanced production of acetic acid from the complex substrates present in BOAP and any potential degradation products that may be generated via fermentation, hydrolysis and other processes. Thus, the benefits of faster flow rate and higher OLR can be better captured through the use of recycle, evidenced by the doubling of the end-point current observed at a loading rate of $3 \mathrm{~g} / \mathrm{L}$-day and $1 \mathrm{~mL} / \mathrm{min}$ flow rate, and a five-fold increase at 10 $\mathrm{g} / \mathrm{L}$-day and $3.6 \mathrm{~mL} / \mathrm{min}$. While the time required for conversion of the BOAP compounds to electrons is an obvious factor limiting current production at higher flow rates under one-pass condition, other factors such as inhibition, mass transfer and/or $\mathrm{pH}$ gradients in biofilm may also be playing a role. The concentration of the substrate used was maintained at $0.026 \mathrm{~g} / \mathrm{L}$, which is relatively low, therefore, substrate inhibition is unlikely to be a factor limiting current production with increased loading. Much higher concentrations of organic acids, furanic and phenolic compounds have been used in bioanode without evidence of inhibition in previous reports [20, 21]. Inhibition due to product may be a possibility since production of protons generated in the anode biofilm generally increases with increasing OLR. Formation of proton gradients within a biofilm in an anode operated under batch conditions has been reported in the literature [22], however, since the MECs used in this study were operated under continuous flow conditions, 
mass transfer due to proton accumulation within the biofilm is likely negligible as $\mathrm{pH}$ values did not drop below 7.1 in the bulk. Furthermore, the increasing flow rate used in the experiments, corresponding to increasing OLRs, helped to ensure this. Mass transfer issues in general would be more of a limitation at the lower flow rates, but low OLRs at these levels helps prevent this. Likewise, higher OLRs where proton accumulation could be more of an issue is prevented by using faster flow rates, thus the low HRT for a complex substrate in one-pass conditions is likely the main culprit for the reduction in current output at the highest flow rate despite enhanced mass transfer conditions. The effect of flow rate on mass transfer is further addressed in section 3.6.

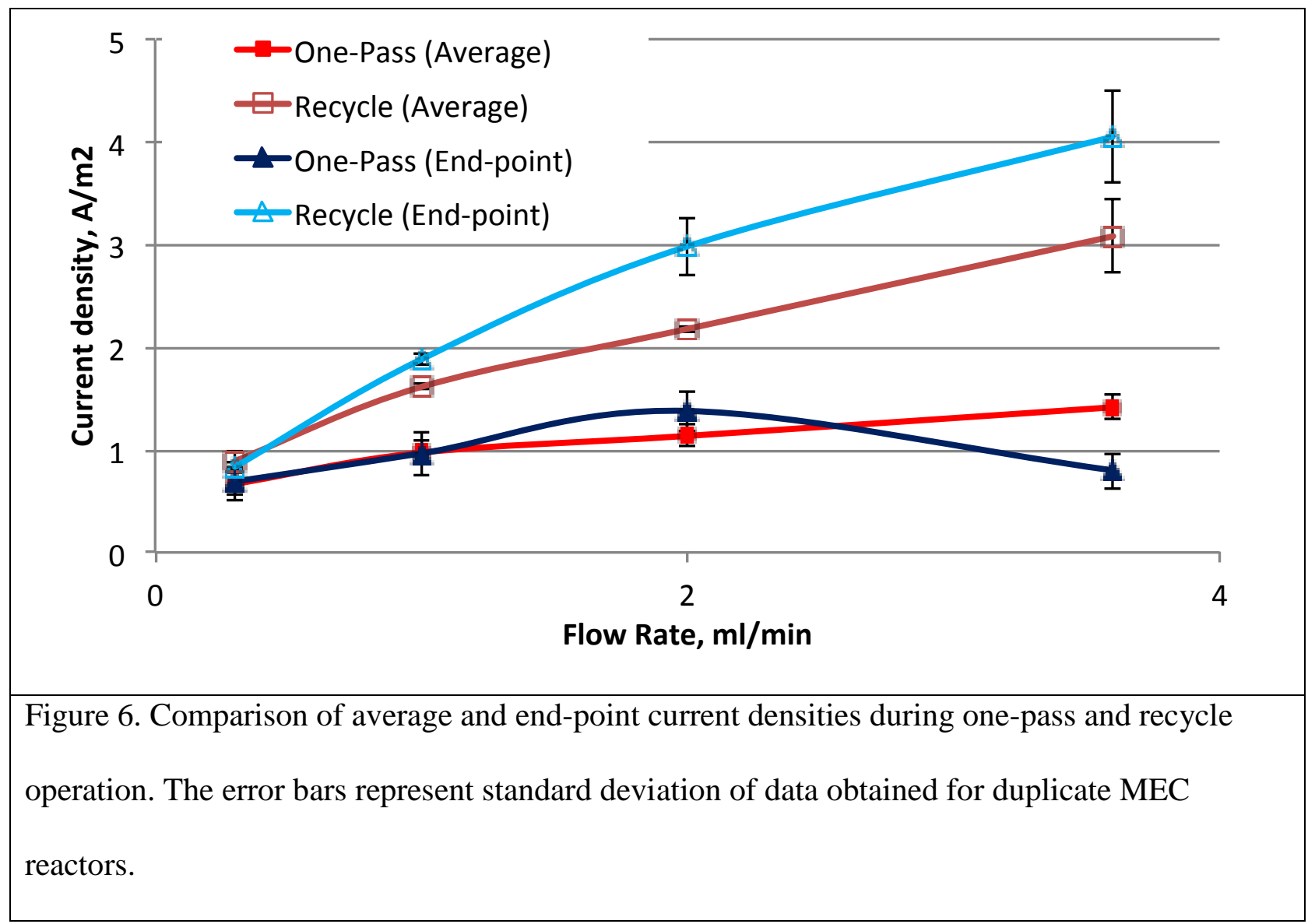


The recycle operation had a significant impact on the conversion efficiencies as well. Figure 7 shows the efficiency parameters for the recycle operation in comparison to the one-pass operation. The ACE increased by $22.4 \%$ at the lowest flow rate of $0.3 \mathrm{~mL} / \mathrm{min}$, when the operation was changed from one-pass to recycle. At the highest flow rate of $3.6 \mathrm{~mL} / \mathrm{min}$, the ACE increased 2.8-fold from $9.9 \pm 0.7 \%$ to $28.1 \pm 2.8 \%$. This demonstrates that recycle of the anode fluid enabled much higher conversion of the BOAP substrate to current as flow rate increased. The HE followed a similar trend, with an increase of $18.4 \%$ at $0.3 \mathrm{~mL} / \mathrm{min}$ and $146 \%$ at $3.6 \mathrm{~mL} / \mathrm{min}$. The average maximum ACE achieved for the MECs combining the results from the replicate reactors was $70.9 \pm 7.9 \%$ and the average maximum $\mathrm{HE}$ was $48.7 \pm 13 \%$. The cathode conversion efficiency was $94.5 \pm 0.7 \%$ at $3.6 \mathrm{~mL} / \mathrm{min}$, which decreased to $68.0 \pm 11.1 \%$ at $0.3 \mathrm{~mL} / \mathrm{min}$. This behavior can be explained in a way similar to that given earlier for the onepass condition. A decrease in cathode half-cell potential was also observed for the recycle experiments with decreasing flow rate and OLR, similar to the one-pass condition, thus reducing the potential difference enabling the cathodic reaction, and limiting cathode efficiency. Furthermore, we have observed in additional experiments (data not shown) that when currents fall below $\sim 1 \mathrm{~mA}$, cathode efficiencies and hydrogen production tend to drop-off significantly regardless of the applied potential, indicating additional factors may be impacting these values. 


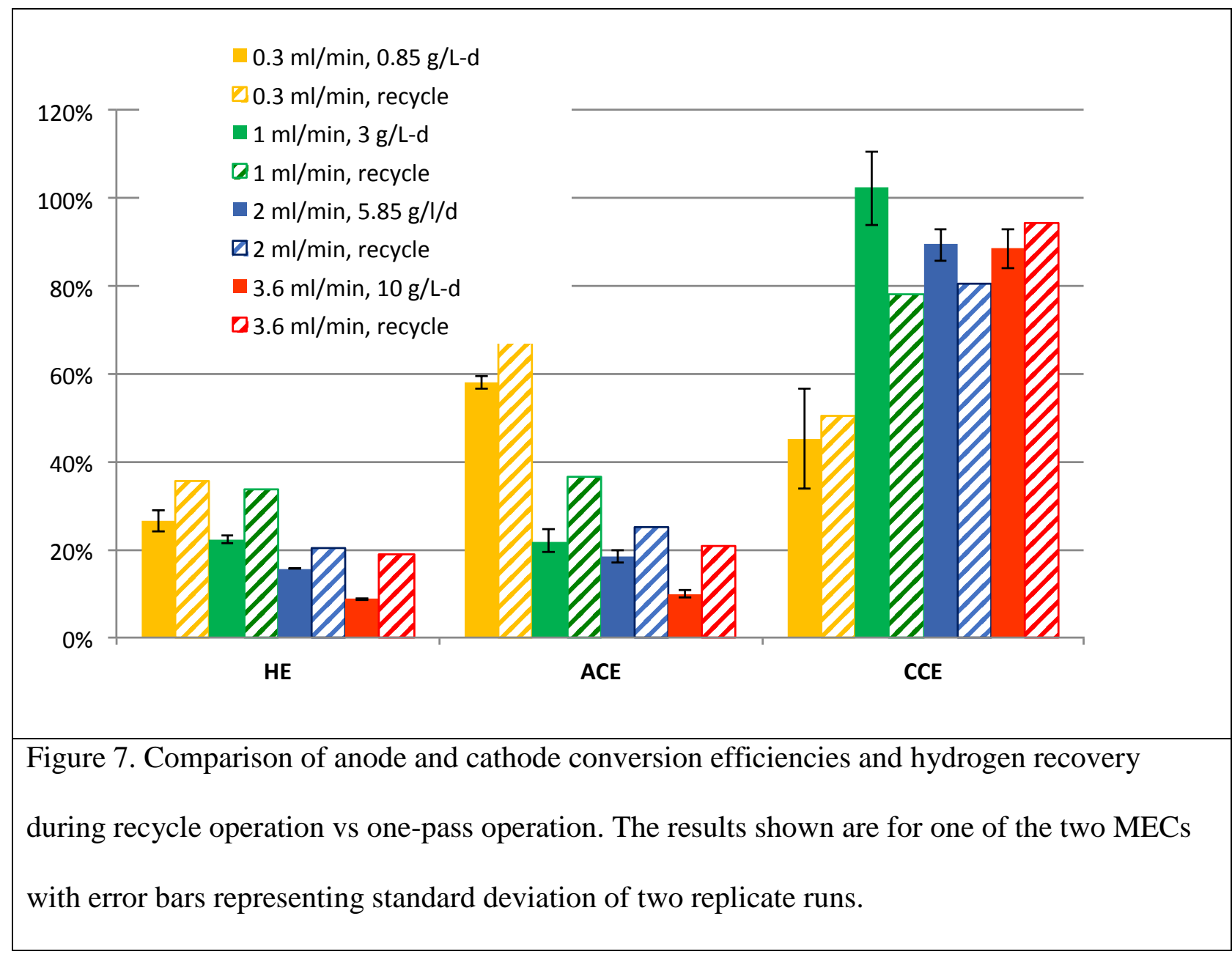

\subsection{COD removal under recycle conditions.}

The recycle operation enabled accumulation of unused substrate in the system, increasing the substrate concentration and COD in the anode liquid with time, until a steady state was reached. Analysis of the COD at the end of the recycle experiments thus allowed calculation of COD removal over the duration of the experiment whereas this was not possible for the one-pass conditions given the low concentration used. Table 1 shows the COD removal under recycle conditions. The COD removal was relatively high ranging from 52.3\% to $74.2 \%$ in the flow rate range of 1 to $3.6 \mathrm{~mL} / \mathrm{min}$. The overall trend of increasing COD removal with flow rate is reverse to that obtained for Coulombic efficiency (CE). At a flow rate of $1 \mathrm{~mL} / \mathrm{min}$ and OLR of $3 \mathrm{~g} / \mathrm{L}-\mathrm{d}$, 
the $\mathrm{CE}$ was $57.63 \% \pm 6.73 \%$, while at $3.6 \mathrm{~mL} / \mathrm{min}$ and $10 \mathrm{~g} / \mathrm{L}-\mathrm{d}, \mathrm{CE}$ was $28.12 \% \pm 2.84 \%$. This indicates that as the flow rate increased, the relative conversion by exoelectrogenesis decreased. This may be due to increase in side reactions such as methanogenesis and/or limitation due to mass transfer. The occurrence of methanogenesis is feasible given the reports on methanogenesis in the literature even at lower concentrations and OLRs $[5,8,23]$. Furthermore, the continued removal of COD at high OLRs indicates that fermentation of compounds within BOAP continued, which would then continue to produce acetic acid as a byproduct. While current output did increase with flow rate indicating that electroactive bacteria were utilizing more acetic acid at each level, the increasing drop in CE indicates that a greater proportion of acetic acid was lost (as it was not found to accumulate), or the additional COD did produce acetic acid as efficiently. This could be the result of side reactions such as methanogenesis or biomass growth with increasing flow rate/OLR. Prior to initiation of the continuous operation studies reported here, the MECs were operated under batch conditions intermittently prior to this study as reported in the Methods section. This may have resulted in the growth of methanogens. Growth of methanogens in the bioanode has been demonstrated by many researchers [24-26] and remains a persistent problem. Additionally, with increased substrate supply diversion of carbon and reducing equivalents for growth could also be contributing to the lower CE. This would support the increased COD removal observed, while diverting less toward current generation to allow growth. Another factor may also be mass transfer/pH limitations due to insufficient proton transfer out of the biofilm. Measurement of the $\mathrm{pH}$ in the bulk anode liquid at the end of recycle operation indicated the $\mathrm{pH}$ to vary between 7.07 and 6.69 , respectively for OLRs between 3 to 10 g/L-day. Calculation of proton accumulation from anodic reaction and accounting for proton consumption in the cathode, it was estimated that the anode $\mathrm{pH}$ would change to 6.6 at the 
highest OLR. Since the observed $\mathrm{pH}$ was 6.69 , it suggests that proton accumulation is likely not responsible for the limited current production or the loss in CE at higher flow rates (Calculations in supplemental information). It is clear that the biofilm was capable of exoelectrogenesis and was not likely limited by substrate or $\mathrm{pH}$. Thus, the most likely reason for the widening gap between COD removal and CE at higher OLR/flow rates may be microbial growth or side reactions such as methanogensis. The measurement of methane in a continuous flow system such as ours was difficult due to the lack of headspace in the anode. However, given the fact that acetic acid was not found to be accumulating at the highest flow rate and OLR despite the low $\mathrm{CE}$, we can say that alternate microbial processes were contributing to the observed electrochemical efficiency loss. Future work will focus on overcoming limitation of our set up in measuring the contributions of methanogenesis and/or other side reactions to COD removal, as well as quantifying possible growth under higher loading.

\begin{tabular}{c|c|c|c|c|c|c}
\hline & $\begin{array}{c}\text { MEC-A } \\
1 \mathrm{ml} / \mathrm{min} \\
3 \mathrm{~g} / \mathrm{L}-\mathrm{d}\end{array}$ & $\begin{array}{c}\text { MEC-B } \\
1 \mathrm{ml} / \mathrm{min} \\
3 \mathrm{~g} / \mathrm{L}-\mathrm{d}\end{array}$ & $\begin{array}{c}\text { MEC-A } \\
2 \mathrm{ml} / \mathrm{min} \\
5.85 \mathrm{~g} / \mathrm{L}-\mathrm{d}\end{array}$ & $\begin{array}{c}\text { MEC-B } \\
2 \mathrm{ml} / \mathrm{min} \\
5.85 \mathrm{~g} / \mathrm{L}-\mathrm{d}\end{array}$ & $\begin{array}{c}\text { MEC-A } \\
3.6 \mathrm{ml} / \mathrm{min} \\
10 \mathrm{~g} / \mathrm{L}-\mathrm{d}\end{array}$ & $\begin{array}{c}\text { MEC-B } \\
3.6 \mathrm{ml} / \mathrm{min} \\
10 \mathrm{~g} / \mathrm{L}-\mathrm{d}\end{array}$ \\
\hline $\mathrm{COD}$ & $69.92 \%$ & $57.65 \%$ & $62.79 \%$ & $52.34 \%$ & $75.03 \%$ & $73.55 \%$ \\
$\mathrm{CE}$ & $52.87 \%$ & $62.39 \%$ & $39.86 \%$ & $48.69 \%$ & $30.12 \%$ & $26.11 \%$ \\
$\mathrm{CCE}$ & $79.20 \%$ & $77.09 \%$ & $84.27 \%$ & $77.26 \%$ & $94.04 \%$ & $95.03 \%$ \\
$\mathrm{HRE}$ & $39.48 \%$ & $27.72 \%$ & $21.09 \%$ & $19.47 \%$ & $21.25 \%$ & $16.56 \%$ \\
\hline
\end{tabular}

Table 1. MEC performance under recycle conditions.

3.5 Understanding the mass transfer implications of setting OLR 
As outlined in the introduction, there are two methods for achieving an increase in OLR (1) increased concentration of substrate, or (2) increased flow rate (reduced HRT). We chose the latter for our main set of experiments keeping concentration constant, but to clearly demonstrate the mass transfer implications of our choice, we carried out additional experiments at $10 \mathrm{~g} / \mathrm{L}-\mathrm{d}$ achieved by changing the concentration instead. At $0.3 \mathrm{~mL} / \mathrm{min}$, a concentration of $0.3 \mathrm{~g} / \mathrm{L}$ is required to achieve an OLR of $10 \mathrm{~g} / \mathrm{L}-\mathrm{d}$, which is $\sim 12 \mathrm{x}$ greater than the concentration needed at a flow rate of $3.6 \mathrm{~mL} / \mathrm{min}(0.026 \mathrm{~g} / \mathrm{L})$ to reach the same OLR. When comparing these two flow rates under one-pass conditions, the end point current density is much lower at the higher flow rate: $\left(0.76\right.$ vs. $3.34 \mathrm{~A} / \mathrm{m}^{2}$, Figure 8$)$. This may appear to be an effect of concentration, since the higher concentration is expected to give a higher current. However, comparison of the current density at the two concentrations under recycle conditions indicates that this may not be the case. The mass transfer effects are masked under one-pass conditions due to the complex nature of the substrate as detailed in previous sections. Under recycle conditions, the end point current density at the higher concentration was $2.9 \mathrm{~A} / \mathrm{m}^{2}$ vs. $4.6 \mathrm{~A} / \mathrm{m}^{2}$ at the lower concentration and higher flow rate. This implies that the flow rate is influencing the current production. Compared to the onepass condition, the recycle condition improves the end point current density 5.7-fold, at the higher flow rate. The observation that higher concentration does not result in higher current implies that mass transfer limitations exist in the MEC. When the flow rate is increased, these limitations are alleviated, resulting in higher current densities, in the case of recycle operation. The same increase in current density is not realized under one-pass condition, because the higher flow rate results in rapid removal of the unconverted BOAP and any intermediates that may be produced by the anodic reaction, which are substrates for exoelectrogenesis. An alternate explanation could be substrate inhibition as the lower flow rate has 10x greater concentration. 
However, substrate inhibition is unlikely to be the reason for reduced current as recent studies have shown much higher concentrations are required for the type of compounds present in BOAP to be inhibitory [20, 21]. Furthermore, our previous work used 0.1 to $0.3 \mathrm{~g} / \mathrm{L}$ BOAP in batch studies and did not see losses in current compared to the lower concentrations tested (4). Mass transfer is thus the likely reason for lower current output at higher concentration and low flow rate. The recycle experiment demonstrates that mass transfer plays a large role in conversion of BOAP, and that the higher flow rate alleviates this limitation. If mass transfer was not an issue, the higher concentration and lower flow rate would have resulted in a higher current in the recycle experiment as well. This also confirms and expands our conclusions made in section 3.3, that the use of recycle can better take advantage of the mass transfer benefits of faster flow rates, and enable better conversion of complex substrates present in BOAP to current. The rate of hydrogen production from complex substrates can thus be influenced more so by introducing recycle than increasing the HRTs. Increasing HRT could increase the hydrogen productivity to a certain extent. Our results indicate that improvements in productivity at higher loading rates (5-20 g/L-day) required for commercial application of MECs [27] would require a combination of recycle with higher flow rates or lower HRTs, especially for complex wastewaters which contain fermentable substrates. A study by Gil-Carrera et al. using municipal wastewater showed that two MECs in series were needed for sufficient removal of COD [6]. In our experiments, a single MEC was used with recycle of the effluent to achieve a similar effect. Use of a two-chamber MEC design allowed higher hydrogen productivity, which was not realized in their study due to use of a membraneless MEC. 


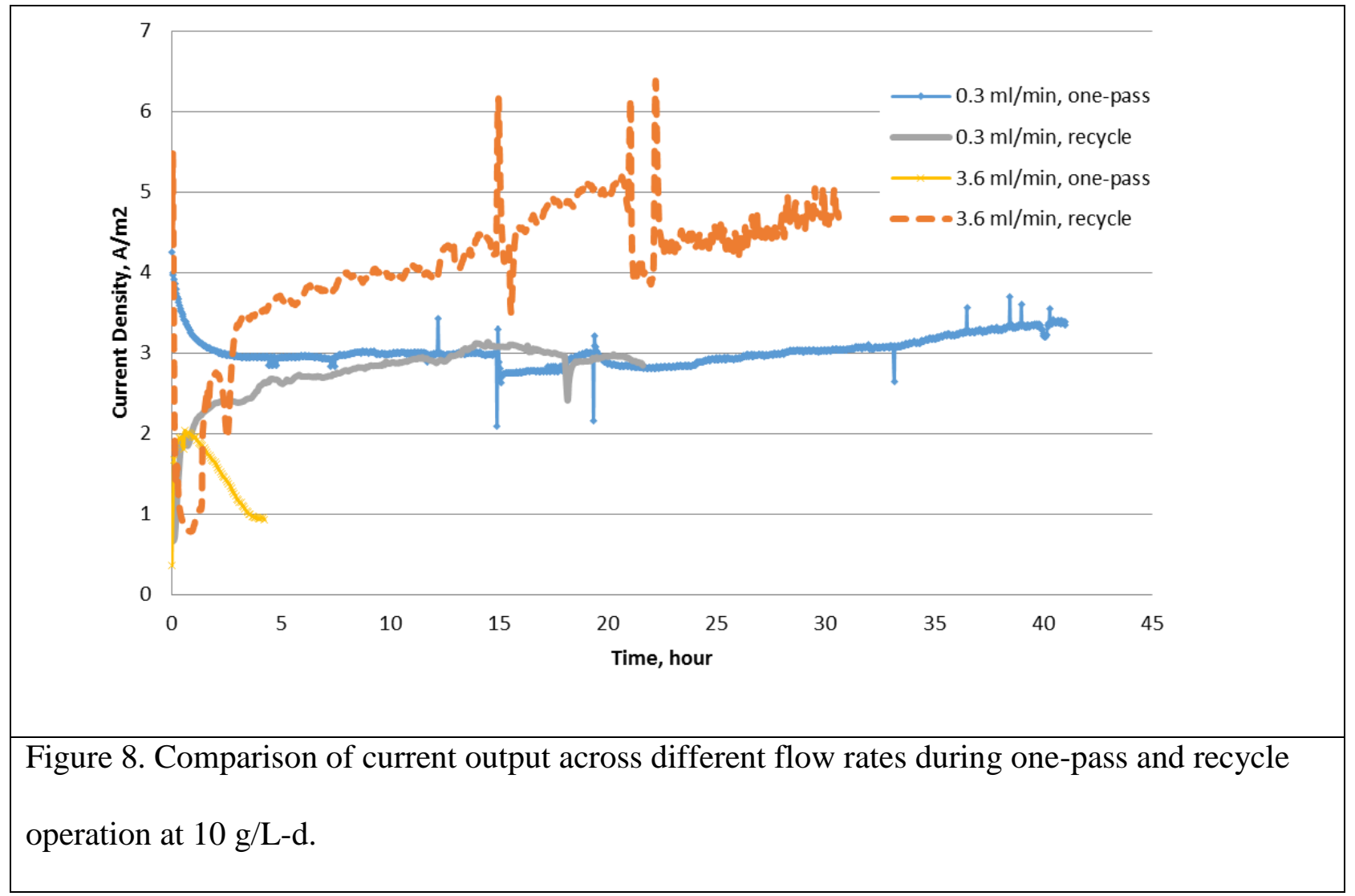

\subsection{Influence of complex fermentable feed stream on MEC performance.}

Conversion of fermentable substrates in the bioanode requires careful consideration of process conditions, which influence mass transfer and kinetics. The BOAP substrate used in this study contains $15 \%$ of the COD as acetic acid, while the remaining compounds represent fermentable substrates of varying recalcitrance. Thus, the ability to catalyze the additional steps from fermentable substrate to acetic acid may be hindered by higher flow rates with less time for conversion under one-pass conditions as outlined in section 3.3. Increased ACE at lower flow rates (and OLRs) indicates a higher proportion of compounds passing through the anode were diverted to current generation, likely through better utilization of easily accessible VFA's like acetic acid, as well as production of acetic acid from other fermentable compounds in BOAP. At 
higher flow rates, utilization of even the easily accessible volatile fatty acids (VFAs) were low, and use of the other fermentable substrates for current production were likely non-existent as ACE was only $~ 9 \%$ under one-pass. The introduction of recycle was shown to improve this, however efficiency was low as described in section 3.4 , likely due to microbial growth or side reactions such as methanogenesis that consumed additional acetic acid produced from recycle compounds. Byproducts generated from the breakdown process were analyzed by HPLC to understand their fate during the recycle operation. The analysis revealed that the anode consortium was capable of consuming the major substrates identified by HPLC in the BOAP feedstock, such as levoglucosan, acetic acid, propionic acid, furfural and hydroxymethylfurfural (HMF). Two intermediates were found to accumulate, but only at higher OLRs. These were phenol and catechol. A recent study investigating furan and phenolic model compounds, such as those present in BOAP, have reported these same compounds to be generated during the degradation of phenolic compounds [21]. In our previous studies, these compounds were found to gradually disappear, over longer term experiments [4] . Zeng et al. (2015) reported that acetate was the primary product of degradation of the model furanic and phenolic compounds [21]. Absence of acetate accumulation in our studies indicates that it was consumed by the members of the anode community, producing current and potentially other products such as methane by methanogenesis as previously stated.

When developing microbial biocatalytic anodes for complex organic streams such as BOAP, there are important structural features and relationships between community members that need to be established in order to efficiently convert the substrates present. Focusing on the two general groups of fermentative and exoelectrogenic bacteria, these functional groups depend on each other and develop syntrophic interactions, with fermenters requiring relief from feedback 
inhibition due to accumulation of organic acid end products [21], and electrogens requiring acetic acid for electrode respiration [5]. Thus, these two groups work together to link fermentation to electricity generation. However, these two groups are not the only functional members that can develop in anode communities. Methanogenic archaea are detrimental organisms in the context of microbial electrolysis that can compete with the exoelectrogenic bacteria for substrate and space in the anode. Operational conditions and variables can significantly impact the conversion and hydrogen production in MECs employing complex fermentable substrates as demonstrated in this study.

\subsection{Implications of MEC integration into biorefinery}

The bio-oil aqueous phase used as a substrate for MEC in this work is a waste product in the pyrolytic biorefinery process, since it cannot be effectively converted into biofuel. It is also a problem for disposal because it has low $\mathrm{pH}$ of about 3.0 and causes instability in the bio-oil intermediate within which it is emulsified. Use of BOAP for hydrogen production solves many problems for the thermochemical biorefinery such as preventing loss of carbon and energy via the aqueous phase, reduction in greenhouse gas emissions via reduced need for natural gas to produce the hydrogen and eliminating wastewater treatment required to remove phenolic and other toxic compounds present in BOAP. MEC can be considered as a process intensification measure as well, since it can reduce the number of unit operations needed in the biorefinery for hydrogen production. A conventional process would require a steam reformer to convert natural gas into hydrogen and a wastewater treatment step to clean the biorefinery effluent. Use of MEC reduces the unit operations, potentially reducing capital costs as well as GHG emissions and energy losses from the thermochemical reforming steps. Implementation of MECs in biorefineries requires continuous operation, which was shown to be feasible in this study. 
However, the need for recycle raises additional questions regarding costs of pumping, which need to be evaluated and compared with existing alternatives to determine the feasibility of the MEC-based biorefinery process.

\section{Conclusion}

Operational parameters impacting a continuous MEC process for hydrogen production in the biorefinery were investigated. Biomass-derived bio-oil aqueous phase was used as the feedstock. Two operational conditions: one-pass and recycle were investigated at varying flow rates (OLR and HRT) with constant substrate concentration. Higher flow rates increased hydrogen productivity by 3 -fold under one-pass conditions, but at the expense of ACE and current output. Both, mass transfer and kinetic limitations were important depending on the operating conditions. One-pass operation masked the mass transfer benefits of faster flow rates since conversion of the complex substrate BOAP, required a longer HRT for multiple conversion steps to generate electrons via synergistic fermentative and exoelectrogenic path, before current production could be realized. Recycle of anode liquid helped alleviate the kinetic issues and improved ACE by $184 \%$, hydrogen productivity by an additional $116 \%$, and end point current by $468 \%$. Additional experiments with a 10x difference in concentration confirmed that the significant increase in endpoint current was a result of a combination of better mass transfer coupled to improved kinetics achieved via recycling, which increased conversion of unconverted substrates and intermediates to electrons, allowing the benefits of faster flow rate to be realized. However, a 51\% loss in CE was observed at higher loading rates despite increased COD removal. This suggests that potential losses via microbial growth and/or methanogenesis may still be occurring. Furthermore, low applied voltages can result in losses in cathode efficiency, 
and reduction in CCE when current is $<1 \mathrm{~mA}$. This study demonstrated that use of high flow rates with recycle can improve conversion of fermentable substrates present in BOAP, improving rate of hydrogen production in MECs.

\section{Acknowledgements.}

Funding from the U.S. Department of Energy, BioEnergy Technologies Office under the Carbon, Hydrogen and Separations Efficiency for Bio-oil Pathways (CHASE) program is acknowledged. AJL was partially supported by the Bredesen Center for Interdisciplinary Research and Education. The manuscript has been co-authored by UT-Battelle, LLC, under Contract No. DEAC05-00OR22725 with the U.S. Department of Energy.

\section{References.}

1. Jones, S., et al., Process design and economics for conversion of lignocellulosic biomass to hydrocarbon fuels. 2013, PNNL.

2. Borole, A.P., Microbial Electrochemical Cells and Biorefinery Energy Efficiency, in Biotechnology for Biofuel Production and Optimization, T. Cong and C. Eckert, Editors. 2016, Elsevier: New York. p. 449-472.

3. Borole, A.P., Improving energy efficiency and enabling water recycle in biorefineries using bioelectrochemical cells. Biofuels, Bioproducts \& Biorefining, 2011. 5(1): p. 28-36.

4. Lewis, A.J., et al., Hydrogen production from switchgrass via an integrated pyrolysis-microbial electrolysis process. Bioresource Technology, 2015. 195: p. 231-241.

5. Gil-Carrera, L., et al., Performance of a semi-pilot tubular microbial electrolysis cell (MEC) under several hydraulic retention times and applied voltages. Bioresource Technology, 2013. 146: $p$. 63-69.

6. Gil-Carrera, L., et al., Reduced energy consumption during low strength domestic wastewater treatment in a semi-pilot tubular microbial electrolysis cell. Journal of Environmental Management, 2013. 122: p. 1-7.

7. Escapa, A., et al., Scaling-up of membraneless microbial electrolysis cells (MECs) for domestic wastewater treatment: Bottlenecks and limitations. Bioresource Technology, 2015. 180: p. 7278. 
8. Cusick, R.D., et al., Performance of a pilot-scale continuous flow microbial electrolysis cell fed winery wastewater. Applied Microbiology and Biotechnology, 2011. 89(6): p. 2053-2063.

9. Ditzig, J., H. Liu, and B.E. Logan, Production of hydrogen from domestic wastewater using a bioelectrochemically assisted microbial reactor (BEAMR). International Journal of Hydrogen Energy, 2007. 32(13): p. 2296-2304.

10. Logan, B.E., et al., Microbial electrolysis cells for high yield hydrogen gas production from organic matter. Environ. Sci. Technol., 2008. 42(23): p. 8630-8640.

11. Tartakovsky, B., et al., High rate membrane-less microbial electrolysis cell for continuous hydrogen production. International Journal of Hydrogen Energy, 2009. 34(2): p. 672-677.

12. Logan, B.E., Scaling up microbial fuel cells and other bioelectrochemical systems. Appl. Microbiol. Biotechnol., 2010. 85: p. 1665-1671.

13. Escapa, A., et al., Hydrogen production and COD elimination rate in a continuous microbial electrolysis cell: The influence of hydraulic retention time and applied voltage. Environmental Progress \& Sustainable Energy, 2013. 32(2): p. 263-268.

14. Escapa, A., et al., Performance of a continuous flow microbial electrolysis cell (MEC) fed with domestic wastewater. Bioresource Technology, 2012. 117: p. 55-62.

15. He, Z., et al., An upflow microbial fuel cell with an interior cathode: Assessment of the internal resistance by impedance Spectroscopy. Environ. Sci. Technol., 2006. 40(17): p. 5212-5217.

16. Aelterman, P., et al., Loading rate and external resistance control the electricity generation of microbial fuel cells with different three-dimensional anodes. Bioresource Technology, 2008. 99(18): p. 8895-8902.

17. Freguia, S., et al., Sequential anode-cathode configuration improves cathodic oxygen reduction and effluent quality of microbial fuel cells. Water Research, 2008. 42(6-7): p. 1387-1396.

18. Borole, A.P., C.Y. Hamilton, and T.A. Vishnivetskaya, Enhancement in energy conversion efficiency and current density of 3-dimensional MFC anodes using pre-enriched consortium and continuous supply of electron donors. . Bioresour. Technol., 2011. 102(8): p. 5098-5104.

19. Ren, S., et al., Analysis of switchgrass-derived bio-oil and associated aqueous phase generated in a semi-pilot scale auger pyrolyzer. Journal of Analytical and Applied Pyrolysis, 2016. in press.

20. Borole, A.P., et al., Controlling accumulation of fermentation inhibitors in biorefinery water recycle using microbial fuel cells. Biotechnol. Biofuels, 2009. 2(1): p. 7.

21. Zeng, X., A.P. Borole, and S.G. Pavlostathis, Biotransformation of furanic and phenolic compounds with hydrogen gas production in a microbial electrolysis cell. Environmental Science \& Technology, 2015. 49(22): p. 13667-13675.

22. Babauta, J.T., et al., $\mathrm{pH}$, redox potential and local biofilm potential microenvironments within Geobacter sulfurreducens biofilms and their roles in electron transfer. Biotechnology and Bioengineering, 2012. 109(10): p. 2651-2662.

23. Gil-Carrera, L., et al., Optimizing the electrode size and arrangement in a microbial electrolysis cell. Bioresource Technology, 2011. 102(20): p. 9593-9598.

24. Freguia, S., et al., Syntrophic Processes Drive the Conversion of Glucose in Microbial Fuel Cell Anodes. Environ Sci Technol., 2008. 42(21): p. 7937-7943.

25. Parameswaran, P., et al., Microbial Community Structure in a Biofilm Anode Fed With a Fermentable Substrate: The Significance of Hydrogen Scavengers. Biotechnology and Bioengineering, 2010. 105(1): p. 69-78.

26. Sleutels, T., et al., Effect of operational parameters on Coulombic efficiency in bioelectrochemical systems. Bioresource Technology, 2011. 102(24): p. 11172-11176.

27. Sleutels, T., et al., Bioelectrochemical Systems: An Outlook for Practical Applications. Chemsuschem, 2012. 5(6): p. 1012-1019. 